\title{
Terapia de presión negativa para cura de escara abdominal en paciente diagnosticada de calcifilaxis
}

\author{
Carmen Fernández González, Beatriz García Alonso, María Belén García Fernández, Lidia Elena Granda \\ Fernández, Carolina López Álvarez, Rocío Castañón Plasín
}

\section{Hospital Central de Asturias (HUCA). Oviedo}

\section{Introducción:}

La calcifilaxis o arteriolopatía urémica calcificante se debe a la calcificación vascular que provoca isquemia/necrosis a nivel de la piel, del tejido celular subcutáneo y los músculos. Es una enfermedad grave con mal pronóstico que puede afectar del 1 al $4 \%$ de la población en diálisis. Los primeros casos fueron descritos en la década de los 60. Las heridas por calcifilaxis son un reto para el personal de enfermería ya que tienen una escasa incidencia a la vez que un mal pronóstico. Además son lesiones muy dolorosas con gran riesgo de infección, siendo la sobre infección y sepsis la principal causa de muerte en estos pacientes. Por eso es tan importante llevar a cabo unos buenos cuidados enfermeros.

\section{Material y método:}

Se presenta un caso clínico en el que se utiliza la terapia de presión negativa para la cura de una placa necrótica abdominal, de gran tamaño, en paciente con Insuficiencia Renal Crónica Avanzada y diagnóstico de calcifilaxis.

\section{Técnica de cura}

La aplicación, a través de una bomba portátil, de presión negativa tópica $(80-100 \mathrm{mmHg}$ ), produce una succión que da lugar a la limpieza de las úlceras, disminuye la carga bacteriana, incrementa el flujo sanguíneo local y favorece el crecimiento del tejido de granulación. Además protege de la contaminación externa. Se limpia la herida con suero, se protege la piel periulceral para evitar que la presión negativa lesione esos tejidos y se coloca la esponja o gasa en el lecho de la herida. Se cubre todo con film trasparente y se coloca la ventosa a través de la cual se realiza el vacío y todo el material succionado pasa a un receptal.

\section{Desarrollo:}

Mujer de 72 años de edad con Insuficiencia Renal Crónica Avanzada que ingresa por placa necrótica que ocupa todo el faldón abdominal. Antecedentes de obesidad, HTA, DM2, hiperparatiroidismo ,... Ingresa en planta en marzo de 2012 con el diagnóstico de calcifilaxis mediante biopsia cutánea. Se pauta hemodiálisis (HD) cinco días a la semana y tiosulfato sódico al $25 \%$ endovenoso después de cada HD (tres dosis semanales). Después de estar realizando durante un mes curas convencionales en ambiente húmedo se decide desbridar la placa necrótica con bisturí, recortando la mitad de la lesión para valorar la evolución. En la siguiente cura se puede observar que todo el tejido graso se ha vuelto a necrosar (abril 2012). Seguimos durante un tiempo con curas según pauta de cura húmeda hasta que en junio de 2012 nos decidimos a desbridar y seguidamente colocamos TPN. Realizamos curas dos veces a la semana, durante cuatro meses, siguiendo la técnica anteriormente mencionada.

\section{Conclusiones:}

La utilización de la TPN supuso una mejoría significativa en el proceso de curación de la herida abdominal. Por la buena evolución que hemos tenido en este caso consideramos que debería valorarse su aplicación en todo paciente que presente úlceras por calcifilaxis. 


\section{Referencias Bibliográficas}

1. Soto PMT, García GMD, Barrios RP. Úlceras vasculares. Calcifilaxis secundaria a insuficiencia renal crónica terminal. 1 st. España: Bubok Publishing; 2012.

2. Marrón B, Coronel F, López-Bran E, Barrientos A. Calcifilaxia: una patogenia incierta y un tratamiento controvertido. Nefrol. 2001; 21 (6): 596-600. Bliss DE. Calciphylaxis: what nurses need to know. Nephrol Nurs j. 2002; 29 (5):433-438, 443-444.

3. Martin R. Mysterious calciphylaxis: wounds wich eschar - to debride or not to debride? Ostomy Wound Manage. 2004; 50 (4): 64-66, 68-70.

4. Gómez de la Fuente E, Vicente FJ, Álvarez J, Elena Naz SI, et al. Calcifilaxis en pacientes dializados. Esp. Card. 2004; 95 (3): 178-182.

5. González HA, Piña SD, Gálvez SM, Gago GMC, Sánchez MJR, Martínez GS, et al. Manifestaciones dérmicas en hemodiálisis. Cuidados de enfermería ¿nuevo enfoque?. Soc. Esp. Enferm. Nefrol. 2005; 8 (4): 326-326.

6. Verdalles GU, Verde E, García de Vinuesa S, Goicoechea M, Mosse A, López GJM, et al. Calcifilaxis: complicación grave del síndrome cardio-metabólico en pacientes con enfermedad renal crónica terminal (ERCT). Nefrol. 2008; 28 (1): 32-36.
7. Polaina RM, Sánchez MMD, Biechy BM, Liébana CA. Calcifilaxis. Sem. Fundac. Esp. Reuma. 2009; 10 (4): 124-127.

8. Rodríguez VI, Callejas R, Sánchez M, Laso N, GaIlar P, Ortega 0, et al. Calcifilaxis o arteriolopatía urémica calcificante: combinación de tratamientos. Nefroplus. 2010; 3 (3): 39-44.

9. Piña SD, González HA, Gálvez SMC, Marco GB, Rubio GE. Actuación de enfermería ante un paciente con calcifilaxis. Soc. Esp. Enferm. Nefrol. 2010; 13 (3): 205-208.

10. Prados SMC, del Pino y Pino MD, Garrófano LR, Moriana DC. Calcifilaxis severa en paciente en hemodiálisis. Diál. Traspl. 2010; 31 (3): 76-78.

11. Vasallo M, Bello I, Hamana L, Ferrer A, Rojas F, Cantele H. Arteriolopatía cálcica urémica: comunicación de un caso y revisión de la literatura. Clín. Esp. $2011 ; 211$ (7): 37-41.

12. Terapia de presión negativa [homepage on the Internet]. España: Smith\&Nephew. Disponible en: http://www.heridas.smith-nephew.es. Malmsjö M, Borgquist 0.TPN opciones de configuración y de apósitos hecha fácil. Wounds International. 2010; 1 (3). Disponible en: http://woundsinternational.com. 